\title{
Intermediate-term precursors of great subduction zone earthquakes: An application for predicting the Tokai earthquake
}

\author{
Tetsuzo Seno \\ Earthquake Research Institute, University of Tokyo, Tokyo 113-0032, Japan
}

(Received November 6, 2003; Revised June 15, 2004; Accepted July 5, 2004)

\begin{abstract}
The Philippine Sea coast of central-southwest Japan tilts oceanward during interseismic periods and peninsulas uplift suddenly at the time of great earthquakes. Tide gauge data indicate that precursory uplifts of the peninsulas occurred during about the decade prior to the occurrence of recent earthquakes. I construct a model to interpret the precursory uplifts on the basis of the model which assumes a fractal distribution of asperities. I calculate uplifts due to slow failures of smaller asperities contained in the rupture zone, assuming that the probability of breakage of the smallest unit asperity increases linearly over time. The time of breakage of one of the largest asperities is the time of the occurrence of a great earthquake, $t_{f}$. I conduct a least squares fitting to the residual uplift data prior to great earthquakes to constrain $t_{f}$. Applications to tide gauge data before the 1923 and 1946 earthquakes give $t_{f}=1923.2( \pm 1.6)$, and $1943.7( \pm 2.7)$, respectively. For the expected Tokai earthquake, I obtain $t_{f}=2007.6$ $(-5.4,+2.8)$ using precise leveling data. The intermediate-term precursors of a decade may be useful to limit the expected time of occurrence of coming great earthquakes, filling the gap between long-term and short-term earthquake predictions.
\end{abstract}

Key words: Prediction, precursor, interplate earthquake, tide gauge, uplift, Philippine Sea, Tokai, Kanto.

\section{Introduction}

Along the Nankai Trough off Central-Southwest Japan, where the Philippine Sea plate (PHS) is subducting beneath the Eurasian plate in the WNW direction at rates of 4-5 cm/yr (Fig. 1, Seno et al. (1993)), great earthquakes have recurred at intervals of 100 to 200 years historically (e.g., Ando, 1975a). At the northernmost part of the Sagami Trough, where the PHS is subducting obliquely at a rate of $3 \mathrm{~cm} / \mathrm{yr}$ (Seno et al., 1993), great earthquakes have recurred with a longer period of 400 years (Kayane and Yoshikawa, 1986). Studies of crustal deformation associated with these events have revealed that the tips of peninsulas on the coast tilt toward the ocean during interseismic periods, and they suddenly uplift at the time of an earthquake (Imamura, 1929; Matsuzawa, 1964). These are interpreted, in terms of plate tectonics, as the overriding plate margin dragged by the subducting PHS suddenly rebounds due to decoupling at the time of an earthquake (Fitch and Scholz, 1971; Ando, 1971, 1975a; Savage, 1983). Long-term prediction programs for great interplate earthquakes in Japan are based on the strategy of detecting risky areas using this periodic interseismiccoseismic crustal deformation pattern (e.g., Rikitake, 1974; Mogi, 1985). For example, in the Tokai district in central Japan (Fig. 1), NW-SE horizontal shortening and seaward tilting of the coast in the Suruga Bay-Enshunada region have been observed since instrument observations in Japan began in the late 1890's. Mogi (1970) noted this area as the location of a coming great earthquake called the Tokai earthquake.

Copy right(c) The Society of Geomagnetism and Earth, Planetary and Space Science (SGEPSS); The Seismological Society of Japan; The Volcanological Society of Japan; The Geodetic Society of Japan; The Japanese Society for Planetary Sciences; TERRAPUB
Ando (1975b) constructed a fault model for this expected event in the Enshunada region. Ishibashi (1981) further elaborated the fault model and shifted it to the northeast based on various newly found data on geomorphology and historical coseismic movements. Since then, traditional geodesy, along with recent GPS velocities, indicates that the NW contraction and tilting of the coast of the Tokai district have been continuing (Yoshioka et al., 1993; Sagiya, 1999; Henry et al., 2001).

Various types of instruments were installed in the Tokai district and their output has been monitored in real-time to detect short-term or immediate precursors of the expected event, since prediction of the Tokai earthquake became a national project. Although it is expected that short-term precursors such as slow uplifts, abnormal strain rates, and foreshocks may occur in a few days to months prior to the mainshock and be detected by instruments such as borehole strainmeters and tiltmeters, it would be still difficult to judge them as precursors in advance.

If intermediate-term precursors are available, they may help somehow the short-term prediction by limiting the period of possible occurrence of the event. In this sense, two kinds of phenomenon have been noted related to intermediate-term precursors of the Tokai earthquake. One is vertical crustal movements such as in the leveling route between Hamaoka and Kakegawa (Fig. 1, inset). Leveling surveys along this route have been carried out repeatedly since 1962 by Geographical Survey Institute, and, in particular, four times per year since 1981 as an aid to earthquake prediction (Geographical Survey Institute, 2000). Steady subsidence of Hamaoka to Kakegawa at a rate of ca. $0.5 \mathrm{~cm} / \mathrm{yr}$ has been detected, which indicates drag of the coast by the 


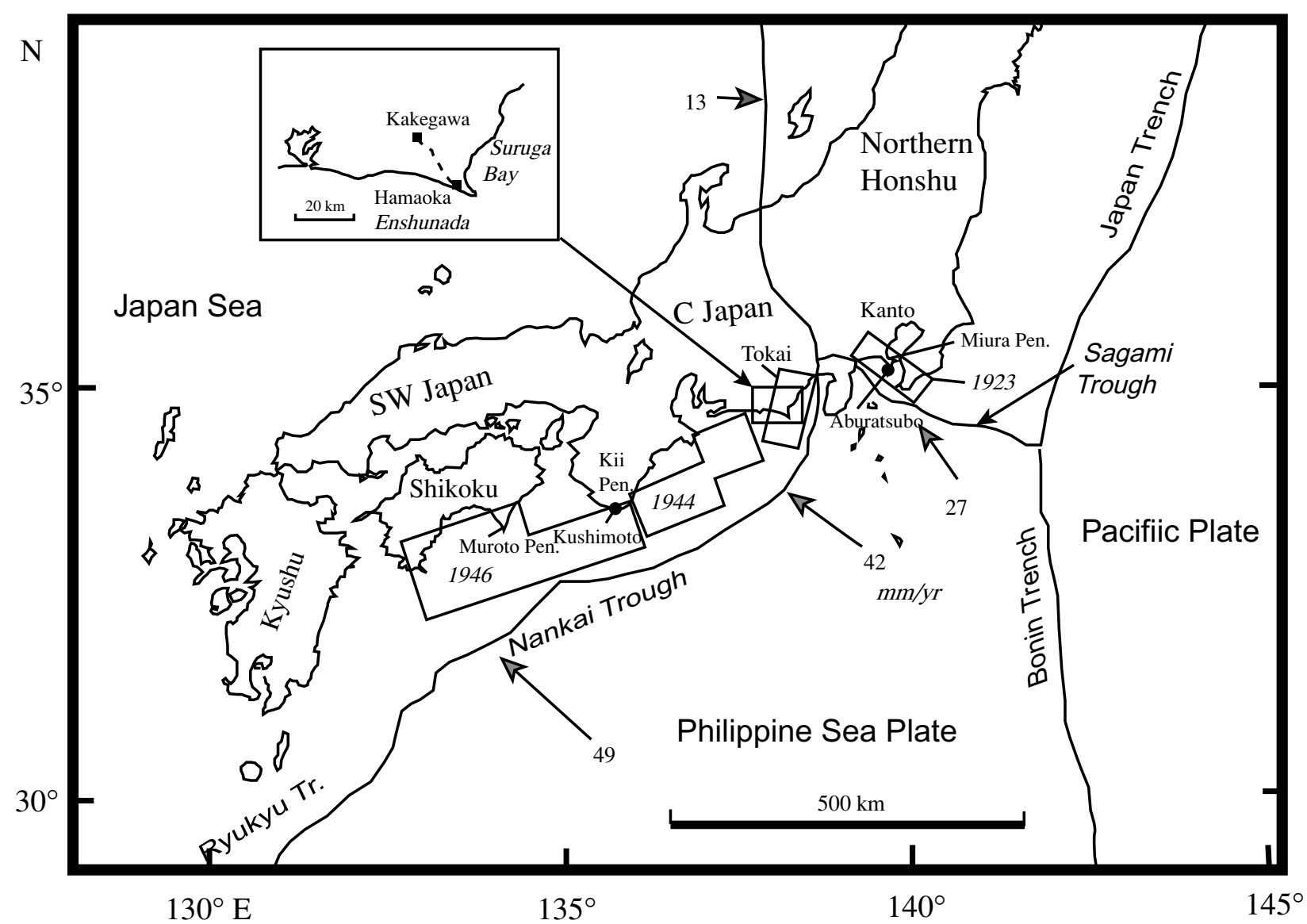

Fig. 1. Index map of Central-Southwest Japan. Fault planes of the 1923, 1944, and 1946 earthquakes (Ando, 1971, 1975a) and that of the expected Tokai earthquake (Ishibashi, 1981), along the Sagami Trough-Nankai Trough, are projected on the horizontal plane. The tide gauge stations at Aburatsubo and Kushimoto are indicated by dots. The leveling route between Hamaoka and Kakegawa is shown in the inset at the upper left. Convergence velocities $(\mathrm{mm} / \mathrm{yr})$ are from Seno et al. (1993).

subducting PHS. Tada (1996) suggested that the subsidence has become mild since the early 1990's, which implies uplifts relative to the steady subsidence (called residual uplifts hereinafter). It has been suggested that similar residual uplifts occurred during the few decades prior to the 1923 Kanto earthquake $\left(M_{w}\right.$ 7.9) from tide gauge data at Aburatsubo on Miura Peninsula (Ohnaka, 1985; Tada, 1996), and prior to the 1946 Nankai earthquake $\left(M_{w} 8.0\right)$ based on leveling and tide gauge data at Muroto Peninsula (Tsubokawa, 1969; Tada, 1996).

Igarashi (2000) applied a power-law formula with a logperiodic modulation (Sornette, 2000), which is generally used in descriptions of critical phenomena, to the residual uplifts of Hamaoka to Kakegawa, and estimated the critical point to be at $2004.7( \pm 1.7)$ year. Unfortunately, the physical basis of his interpretation as a critical phenomenon is not clear, making it difficult to judge the trustworthiness of his prediction. The residual uplifts were also modeled by Kawasaki and Okada (2001) and Ariyoshi et al. (2001), on the theoretical basis of rupture nucleation (Ohnaka and Shen, 1999) and pre-slip of faulting with rate and state dependent friction laws (Dieterich, 1979; Ruina, 1983), respectively. The time-scales of the precursory residual uplifts predicted by these theories are a few months to a few years at most, which are shorter than observed. Stuart (1988) also showed that the time-scale of intermediate-term precursory crustal movements prior to the 1946 Nankai earthquake, based on the slip model with rate and state dependent friction laws, is shorter than a few years except at stations very close $(\sim 10$ $\mathrm{km})$ to the surface fault trace.

The other phenomenon is the quiescence of seismic activity in the focal region of the expected event. Matsumura (2002) noted that an abnormal reduction in seismicity rate started in the mid-1990's within the upper plate in the focal region, suggesting a change in stress state. Applying an empirical relation between quiescent periods and areas of asperities derived from earthquakes in the U.S., he inferred that the next event might occur within a few to several years. Because the physical basis of the relation between quiescent periods and asperity sizes is not clear, it is also difficult to put trust in his prediction.

In this paper, I construct a physical model to interpret the residual uplifts prior to great interplate earthquakes. The model is based on an idea proposed in a companion paper (Paper I, Seno, 2003), which assumes a fractal distribution of asperities and temporal changes of the frictional property of barriers in fault zones along plate boundaries. The fractal geometry of asperities was determined in Paper I using data of interplate earthquakes along the San Andreas fault and near Japan.

Within the framework of this model, I calculate residual uplifts due to slow failures of smaller asperities contained in 


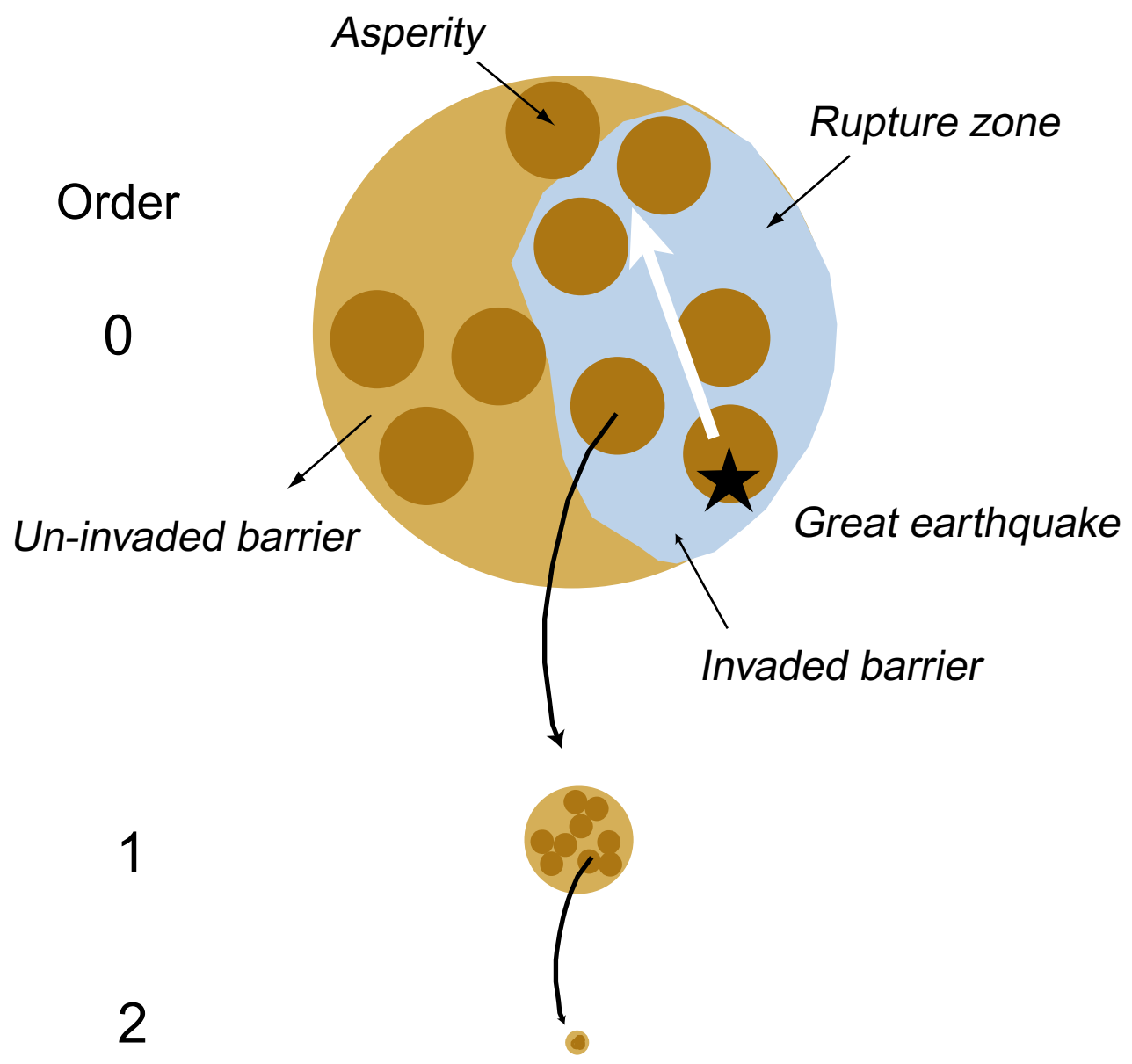

Fig. 2. Fractal geometry of asperities. An asperity is assumed to have a circular shape. An order $n$ asperity contains a number of $N_{a}$ order $n+1$ asperities. The ratio of radius between order $n$ and order $n+1$ asperities, i.e., $R_{n} / R_{n+1}$, is $\lambda . N_{a}$ and $\lambda$ determine the fractal geometry of asperities. The region where barriers are invaded is lightly shaded and can produce an earthquake. The degree of an earthquake is defined by the number of one order larger asperities inside.

the largest asperities in a focal region of a great earthquake, assuming an interaction between failures of successive-size asperities. This is then used for predicting the time of breakage of one of the largest asperities, which is the occurrence time of an earthquake, by best-fitting the calculated uplifts to observed data. I first describe the model assumptions and the scaling relations, which are fully described in $\mathrm{Pa}-$ per I, and next, some additional assumptions made in this paper and procedures of calculation of residual uplifts. I apply the method to the observed tide gauge data prior to the 1923 Kanto and 1946 Nankai earthquakes, to predict (postdict) the occurrence times of these earthquakes. Finally, I apply the method to the precise leveling data from Hamaoka to Kakegawa, and predict the occurrence time of the expected Tokai earthquake.

\section{Model and Scaling Relations}

The model in Paper I has the following basic assumptions: (1) Plate boundary fault zones consist of asperities and barriers, which are defined as having negative and positive $a-b$ values, respectively, of rate and state dependent friction laws (Dieterich, 1979; Ruina, 1983). Note that barriers defined here are different from the high cohesive strength areas (hard barriers) originally defined by Das and Aki (1977). They are soft barriers because when an asperity breaks, the surround- ing barriers do not slip instantaneously, but gradually slip to relieve the load (Tse and Rice, 1986; Boatwright and Cocco, 1996; Kato and Hirasawa, 1999). (2) Circular-shaped asperities are distributed in a fractal manner (Fig. 2). This comes from the fact that the scaling relation between the seismic moment and fault area derived in Paper I requires the fractal distribution of asperities (see also Sammis et al., 1999). This is also consistent with the fractal contact areas of rock specimens (Dieterich and Kilgore, 1996). (3) Pore fluid pressure can be elevated almost to the lithostatic only in barriers (called invasion of barriers). Elevated pore fluid pressure in fault zones would be one of the most plausible factors to help to reduce rock strength by reducing effective normal stresses $\sigma_{n}^{*}=\sigma_{n}-p$, where $p$ is the pore fluid pressure and $\sigma_{n}$ is the normal stress (see the literature cited in Paper I). Paper I assumed that only barriers have such characteristics to avoid the overall stabilization. (4) A region in which barriers are invaded can rupture as an earthquake when one of asperities inside breaks. Fig. 2 (upper) shows asperities surrounded by invaded barriers. Because barriers have lost friction, rupture of an asperity is propagated to others. This mode of rupture is called "earthquake mode". If barriers are not invaded, asperities break slowly by the objection of barriers. This mode of rupture is called "slow failure mode".

The "order" of an asperity is introduced such that an order 




Fig. 3. Probabilities of breakage of order 7 to 2 asperities versus a probability of breakage of an order 7 asperity (denoted by $p$ ), calculated for $N_{a}=9$ and $N_{b}=4$. A critical point appears at $p=0.322$.

0 asperity is the largest, and within an order $n$ asperity, a number of $N_{a}$ order $n+1$ asperities are contained, whose radius is $1 / \lambda$ of that of an order $n$ asperity (Fig. 2). Let barriers in the lightly shaded part of an order $n$ asperity be invaded (Fig. 2). This area can rupture as an earthquake, and the order of this earthquake is defined as $n$. The "degree" of this event is defined by the number of order $n+1$ asperities within the rupture zone. Then, the maximum degree of an earthquake is $N_{a}$ and the minimum is 1 . Note that an order $n+1$ asperity also contains order $n+2$ asperities and surrounding barriers inside (Fig. 2).

Here, I summarize the scaling relations of various fault parameters for slow failures of asperities between order $n$ and order $n+1$ asperities, obtained in Paper I. Areas, $A_{n}$ and $A_{n+1}$, have the relation

$$
A_{n+1}=\left(1 / \lambda^{2}\right) A_{n} .
$$

Shear strength $\tau_{n}$ over an order $n$ asperity is related to $\tau_{n+1}$ over an order $n+1$ asperity, from the force balance, as

$$
\tau_{n+1}=\left(\lambda^{2} / N_{a}\right) \tau_{n}
$$

Assume that strength $\tau_{n}$ is totally relieved as a stress drop $\Delta \sigma_{n}$ when an order $n$ asperity fails slowly, and let the displacement associated with the slow failure of an order $n$ asperity be $d_{n}$. Equations (1) and (2), and $\Delta \sigma_{n} \sim d_{n} / A_{n}^{0.5}$ lead to

$$
d_{n+1}=\left(\lambda / N_{a}\right) d_{n}
$$

Finally, moment $M_{o n}$ associated with the slow failure is related to $d_{n}$ and $A_{n}$ by $M_{o n}=\mu d_{n} A_{n}$, where $\mu$ is the rigidity. Equations (1) and (3) lead to

$$
M_{o n+1}=M_{o n} /\left(\lambda N_{a}\right) .
$$

The fractal dimension $D$ of asperities is, as shown in Paper I, given by

$$
D=\log \left(N_{a}\right) / \log (\lambda) .
$$

Earthquakes have slightly different scaling relations from those of the slow failure above. When an order $n$ degree $i$ earthquake occurs as breakage of isolated asperities within an invaded barrier region (Fig. 2), broken order $n+1$ asperities produce isolated stress drops. Then, moment $M_{o n}^{i}$ and fault area $A_{n}^{i}$ of an order $n$ degree $i$ earthquake are

$$
M_{o n}^{i}=i M_{o n+1}
$$

and

$$
A_{n}^{i}=\left(i / N_{a}\right) A_{n},
$$

respectively. The total moment of a degree $N_{a}$ order $n$ earthquake is $N_{a} M_{o n+1}$, which equals $M_{o n} / \lambda$ from Eq.(4).

Paper I showed that the relation between the fault area and the seismic moment derived from interplate earthquakes along the San Andreas fault and near Japan constrain the values of $\lambda, D$, and $N_{a}$ as $4.8,1.4$, and 9 , respectively. 


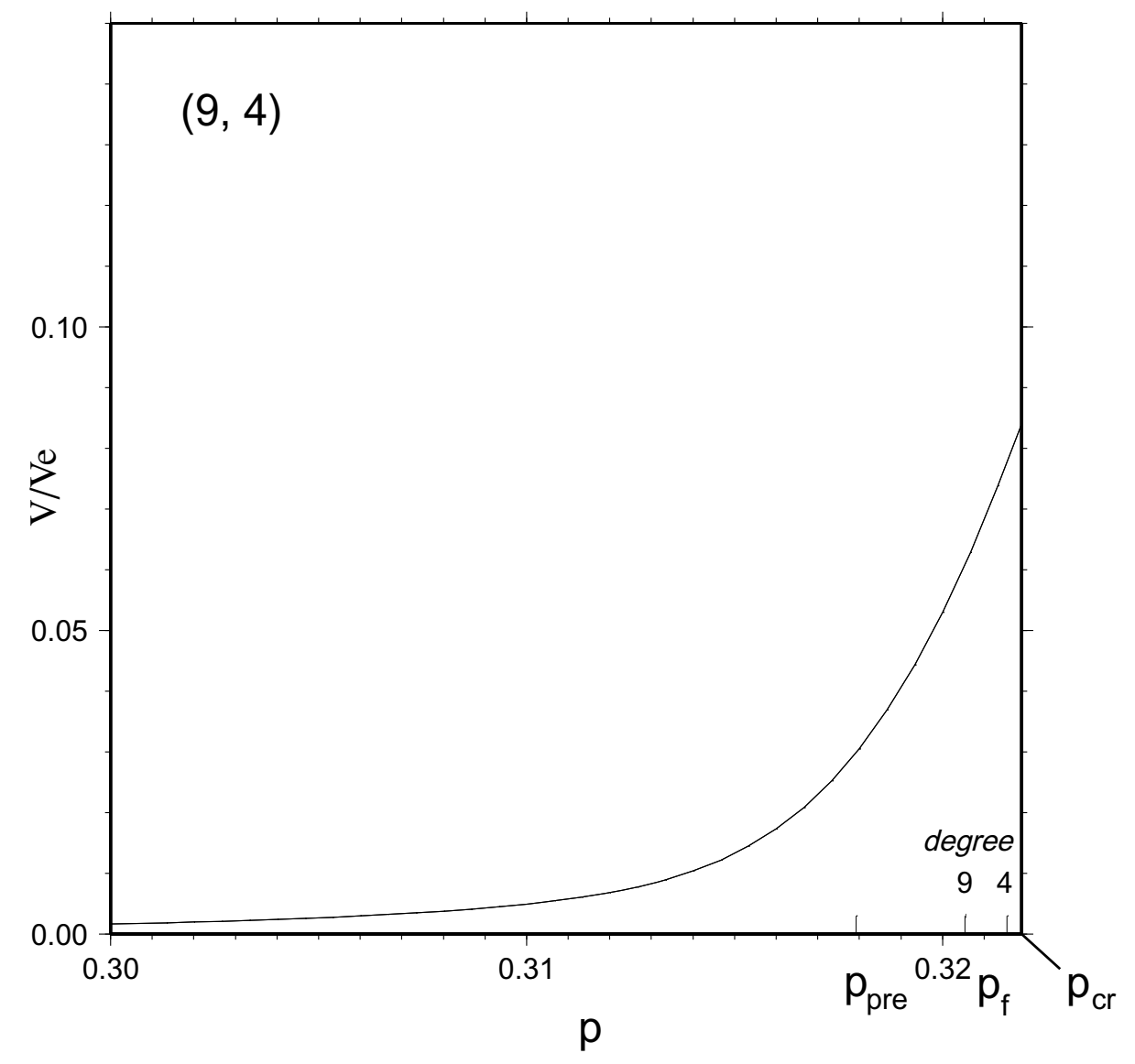

Fig. 4. Plot of $V / V_{e}$ versus $p$ for $N_{a}=9$ and $N_{b}=4$. Locations of $p=p_{f}$ for degrees 4 and 9 are indicated by small bars. Location of $p_{p r e}$ for $V_{e} / V=0.03$ is shown by a small bar. This location corresponds to the last data point for the Tokai earthquake, when $V_{e}=60 \mathrm{~cm}$.

\section{Additional Assumptions}

In addition to the model assumptions stated in Paper I, I describe here a few more assumptions made in this paper to calculate residual uplifts prior to great earthquakes.

\subsection{Invasion mode prior to a great earthquake}

Let the rupture zone of a great earthquake be part of an order 0 asperity (see the scaling of earthquake size in table 2 of Paper I), which includes a number of $i$ order 1 asperities. This earthquake is then an order 0 degree $i$ earthquake (Fig. 2). Because I calculate an intermediate-term uplift prior to this earthquake, I assume that the barriers surrounding the order 1 asperities in the rupture zone have already been invaded. Then the earthquake will occur when one of these order 1 asperities breaks. On the other hand, I assume that barriers inside any of these order 1 asperity are not invaded (Fig. 2, bottom) because, if they are invaded, failure of an order 2 asperity inside such an order 1 asperity leads to a breakage of this order 1 asperity in earthquake mode, which further leads to much earlier occurrence of the earthquake. Therefore I assume that smaller asperities fail slowly, and finally one of the order 1 asperities fails slowly, resulting in a great earthquake. The quiescence seen in the focal regions of great earthquakes prior to their occurrence (Mogi, 1969) might give some credit to this assumption.

\subsection{Interaction between slow failures of successive or- der asperities}

Let assume now that no barrier is invaded within asperities for $n \geq 1$; i.e., these asperities fail slowly. Provided that an order $n$ asperity contains $N_{a}$ order $n+1$ asperities, failure of some of the order $n+1$ asperities inside will bring the breakage of the order $n$ asperity, when the stress concentration of the unbroken order $n+1$ asperities overcomes their strength. Therefore order $n+1$ asperities interact with the order $n$ asperity that contains them. As for the interaction between slow failures of successive order asperities, I assume that an order $n$ asperity fails when more than or equal to $N_{b}$ order $n+1$ asperities inside it fail. This assumption is similar to that used by Allegre et al. (1982) to model a fracture of a crustal block that has fractal sub-blocks. In their model, when more than some number of sub-blocks are failed, the larger block that contains them fails. $N_{b}$ is generally smaller than $N_{a}$ because as the number of broken asperities within an order $n$ asperity increases, the shear stress $\tau$ on the unbroken asperities increases dramatically. $N_{b}$ would be neither a small number, because instability easily occurs in such cases. I will show later that $N_{b}$ is restricted to nearly half of $N_{a}$.

Letting probability of breakage of an order $n$ asperity be $p_{n}$, the relation between $p_{n}$ and $p_{n+1}$ is then

$$
\begin{aligned}
p_{n}=f\left(p_{n+1}\right)= & { }_{N a} \mathrm{C}_{N a} p_{n+1}^{N a}+{ }_{N a} \mathrm{C}_{N a-1} p_{n+1}^{N a-1}\left(1-p_{n+1}\right) \\
& +{ }_{N a} \mathrm{C}_{N a-2} p_{n+1}^{N a-2}\left(1-p_{n+1}\right)^{2}+\cdots \\
& +{ }_{N a} \mathrm{C}_{N b} p_{n+1}{ }^{N b}\left(1-p_{n+1}\right)^{N a-N b}
\end{aligned}
$$

where ${ }_{N a} \mathrm{C}_{N a-i}$ is a binomial coefficient. Letting the order and the probability of breakage of the smallest asperity be $N_{\max }$ and $p_{N \max }=p$, respectively, probabilities of break- 


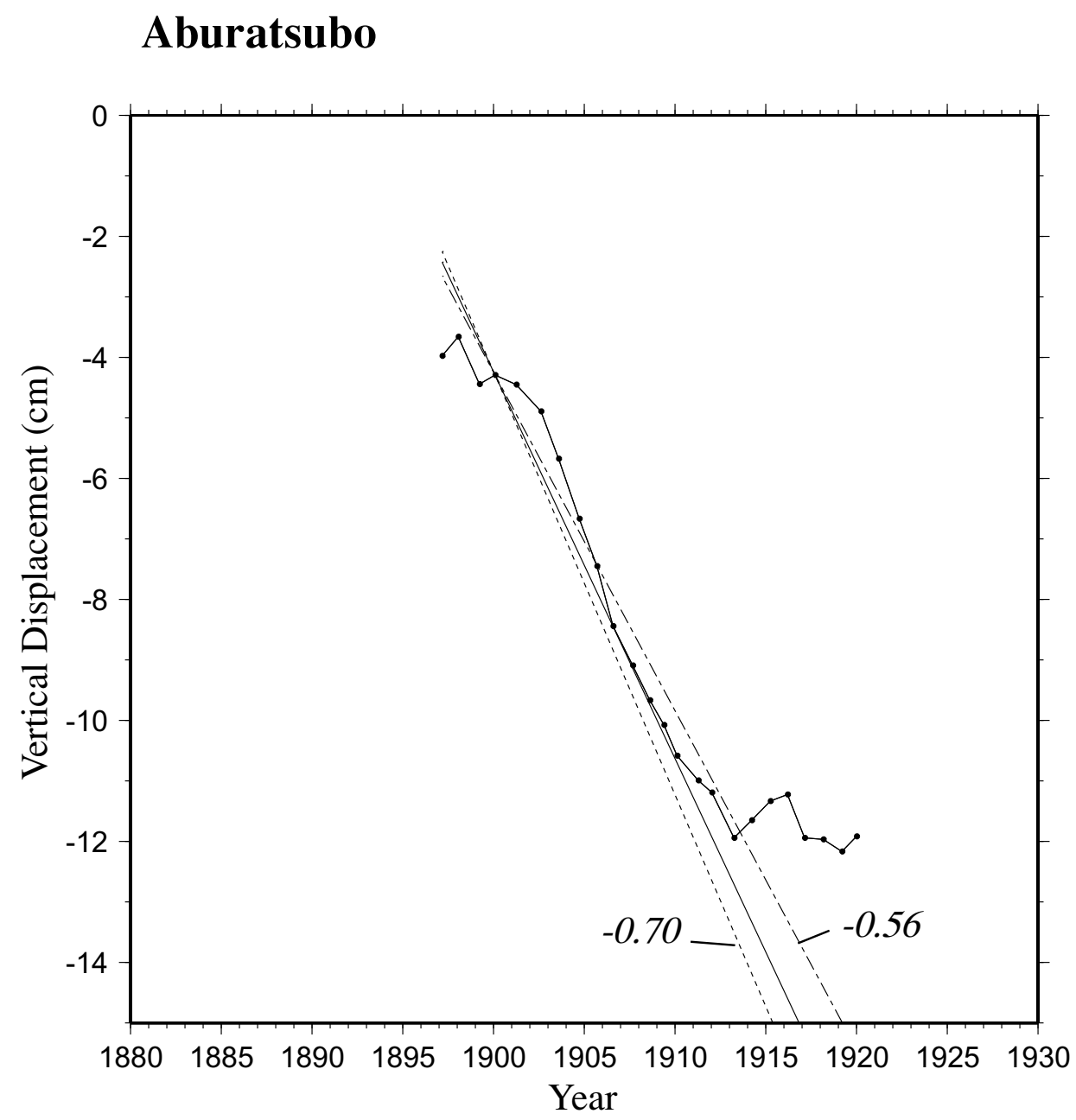

Fig. 5. Tide gauge data at Aburatsubo before the 1923 Kanto earthquake (Coastal Movements Data Center, 2000). The signs are reversed and running-averaged for five points. The dotted and chain lines indicate the $1 \sigma$ error range of the subsidence rate $v_{s}$. The solid line indicates $v_{s}$ with the minimum $\chi^{2}$. Numerals are in $\mathrm{cm} / \mathrm{yr}$. The residual uplifts became evident around 1913 .

age of any larger (smaller order) asperity can be calculated applying Eq. (8) successively. Figure 3 plots the probabilities of breakages of order 7 to order 2 asperities versus $p$, when $N_{\max }=7, N_{a}=9$ and $N_{b}=4$. In this case, a critical point appears at $p=0.322$ where probabilities of breakage become equal for all the orders (Fig. 3; see also Allegre et al., 1982); thus the model includes critical phenomena. Order 7 corresponds to the smallest repeating earthquakes in the Parkfield area in the San Andreas (Nadeau and Johnson, 1998; see Paper I); I use then $N_{\max }=7$ for the following calculations.

\section{Calculation of Uplift}

Once probabilities $p_{n}\left(n=2 \sim N_{\max }\right)$ of slow failures of order $n$ asperities are given, it is possible to calculate the crustal deformation due to total failures prior to the failure of one of order 1 asperities. Let observed coseismic deformation at some location be $V_{e}$, which may be obtained from precedent earthquakes or be inferred from a fault model. This amount of $V_{e}$ is caused by failures of $i$ isolated order 1 asperities with a total moment of $i M_{o 1}$. This gives an amount of deformation $V_{1}$ due to failure of an order 1 asperity with a moment $M_{o 1}$ as $V_{e} / i$. Using scaling relation (4), $V_{n}$, deformation due to failure of an order $n$ asperity, can be obtained as $V_{2}=V_{1} /\left(\lambda N_{a}\right), \ldots, V_{N \max }=V_{N \max -1} /\left(\lambda N_{a}\right)$. Then the total crustal deformation due to failures of order $n$ asperities with a probability of breakage of $p_{n}\left(n=2 \sim N_{\max }\right)$ is

$$
\begin{aligned}
V & =i\left(V_{2} N_{a} p_{2}+\cdots+V_{n} N_{a}^{n-1} p_{n}+\cdots+V_{N \text { max }} N_{a}^{N \max -1} p_{N \max }\right) \\
& =V_{e}\left\{(\lambda)^{-1} p_{2}+\cdots+(\lambda)^{-n+1} p_{n}+\cdots+(\lambda)^{-N \max +1} p_{N \text { max }}\right\} .
\end{aligned}
$$

$V / V_{e}$ is shown as a function of $p$ in Fig. 4 for $N_{a}=9$, $\lambda=4.8$, and $N_{b}=4 . V / V_{e}$ has a critical exponent of 1 near the critical point $p_{c r}$. The earthquake occurs, however, when one of the $i$ order 1 asperities is expected to break, that is when $p_{1}=1 / i$. Let $p$ giving this $p_{1}$ be $p_{f}$. The locations of $p_{f}$ for $i=4$ and 9 are indicated by bars in Fig. 4. For degrees less than or equal to $3, p_{1}$ becomes larger than $p_{c r}$, which is not allowed in the model because breakage of an order 0 asperity occurs before that of an order 1 asperity. I, therefore, neglect such cases and treat only cases of $i>3$.

If $V_{e}$ is given and $p$ is converted to time $t$, I can calculate $V$ through Eq. (9) and compare it to precursory crustal movement data. $p$ is converted to $t$ as follows. Assume that $p$ increases linearly in $t$. Letting $V_{\text {pre }}$ be the final available data point at $t=t_{\text {pre }}$, I can get probability $p=p_{\text {pre }}$ which gives $V_{\text {pre }}$ through Eq. (9). I indicate $p_{\text {pre }}$ for $V_{\text {pre }} / V_{e}=0.03$, for 


\section{Aburatsubo}

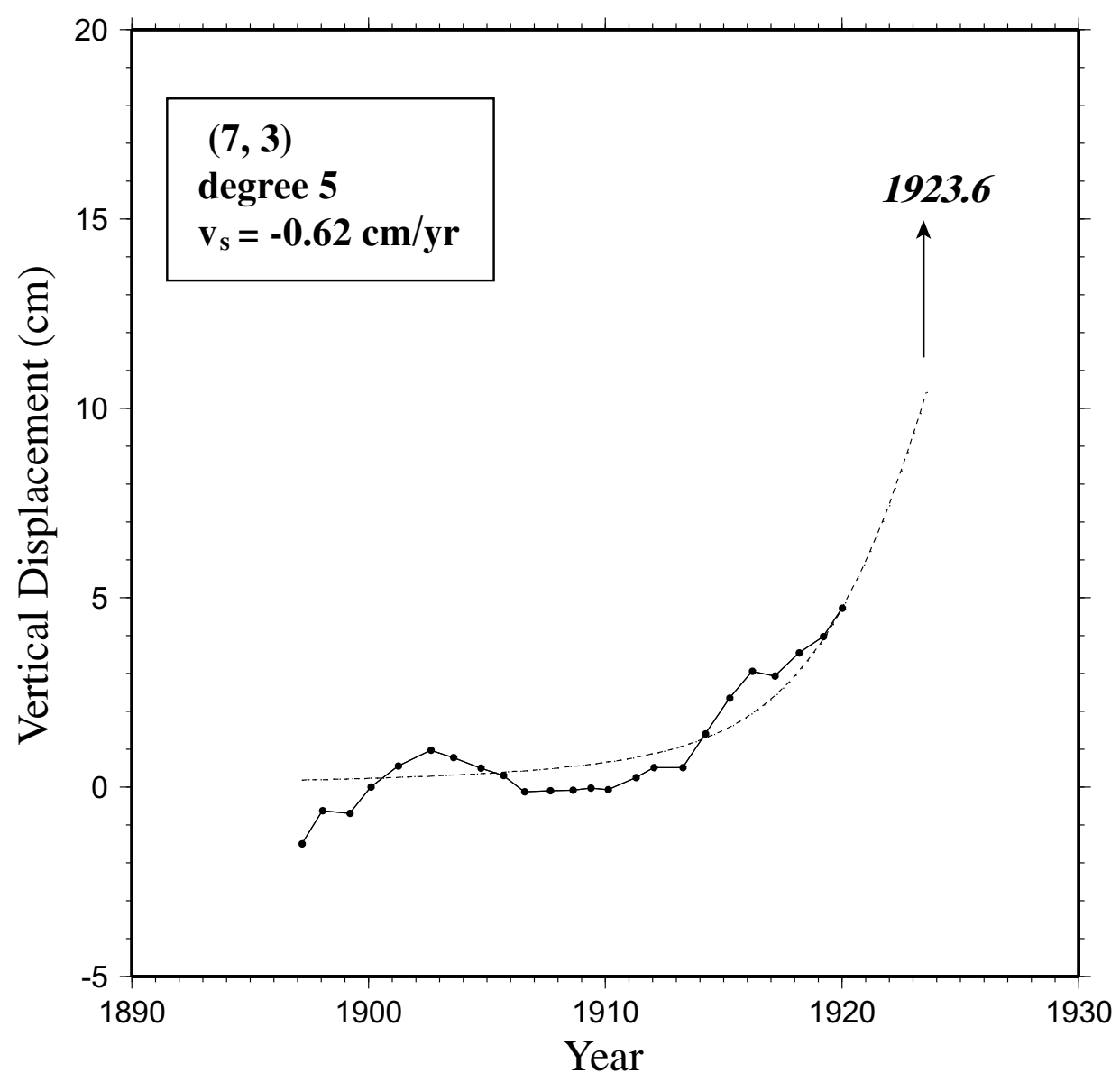

Fig. 6. Residual uplifts for $v_{s}=-0.62 \mathrm{~cm} / \mathrm{yr}$, with the best-fitting curve for $(7,3)$ and $i=5$, which gives $t_{f}=1923.6$.

example, in Fig. 4. Introducing $t_{f}$ as a parameter representing the time of $p=p_{f}, p$ can be converted to $t$. Calculating $V$ as a function of $t$ using Eq. (9), best-fit for the observed data constrains parameter $t_{f}$.

The choice of $N_{b}$ affects the distribution of the probabilities shown in Fig. 3 through Eq. (8), and thus affects the residual uplift curve shown in Fig. 4. I show later that the values of $N_{b}$ larger than a half of $N_{a}$ are rejected because they produce larger misfits.

\section{The 1923 and 1946 Earthquakes}

The 1923 Kanto earthquake occurred on Sept. 1, 1923 (1923.7) along the northernmost portion of the Sagami Trough (Fig. 1), which led to the worst disaster (ca. 140,000 casualties) among historical earthquakes in Japan. Figure 5 shows the tide gauge data at Aburatsubo before the 1923 event, for which signs are reversed and running-averaged over 5 points (Coastal Movements Data Center, 2000). I regard these as representing the vertical movement at this point, neglecting oceanographic effects. Around 1913, a deviation from the steady subsidence became evident.

I apply the above method to predict the time of occurrence of the 1923 earthquake, $t_{f}$, using the data in Fig. 5; the data covers the period from 1897.2 through 1920.0. To recover the residual uplifts, the steady subsidence is assigned within the range of subsidence rate, $v_{s}$, between -0.74 and -0.54 $\mathrm{cm} / \mathrm{yr}$, through the fourth data point. It is known that Aburatsubo uplifted by $140 \mathrm{~cm}$ coseismically with respect to the last data point (Ohnaka, 1985). I assigned $135 \mathrm{~cm}$ as $V_{e}$ because an additional uplift of about $5 \mathrm{~cm}$ occurs in the model calculation before $t_{f}$ after the last data point. Although $N_{a}$ was determined to be 9 in Paper I, I also use $N_{a}=7$, taking into account possible errors in determining $\lambda$. $\lambda$ is 4.0 for $N_{a}=7$ from Eq. (5), with $D=1.4$. Cases of $N_{a}<7$ give too large $\chi^{2}$, and are not considered; it is also shown in Paper I that smaller $N_{a}$ is not consistent with the seismic observations. For $N_{a}=9$, cases of $N_{b}>4$ make $\chi^{2}$ larger by 1.66 than that of $N_{b}=4$. On the other hand, in cases of $N_{b}<4$, instability easily occurs, and $p_{1}$ becomes larger than $p_{c r}$. Thus, I only consider the case of $N_{b}=4$ for $N_{a}=9$. Similarly, I only consider the case of $N_{b}=3$ for $N_{a}=7$. These cases are denoted by $(9,4)$ and $(7,3)$, respectively. The earthquake degree is perturbed between 4 and $N_{a}$ as smaller degrees give larger $p_{1}$ than $p_{c r}$ as stated before.

$v_{s}=-0.64(-0.06,+0.08) \mathrm{cm} / \mathrm{yr}$ and $-0.62(-0.08$, $+0.06) \mathrm{cm} / \mathrm{yr}$ give the minimum $\chi^{2}$ for $(9,4)$ and $(7,3)$, respectively. The parentheses are $1 \sigma$ errors when $\sigma$ of the data is assigned to be $1 \mathrm{~cm}$. These values do not depend on 


\section{Kushimoto}

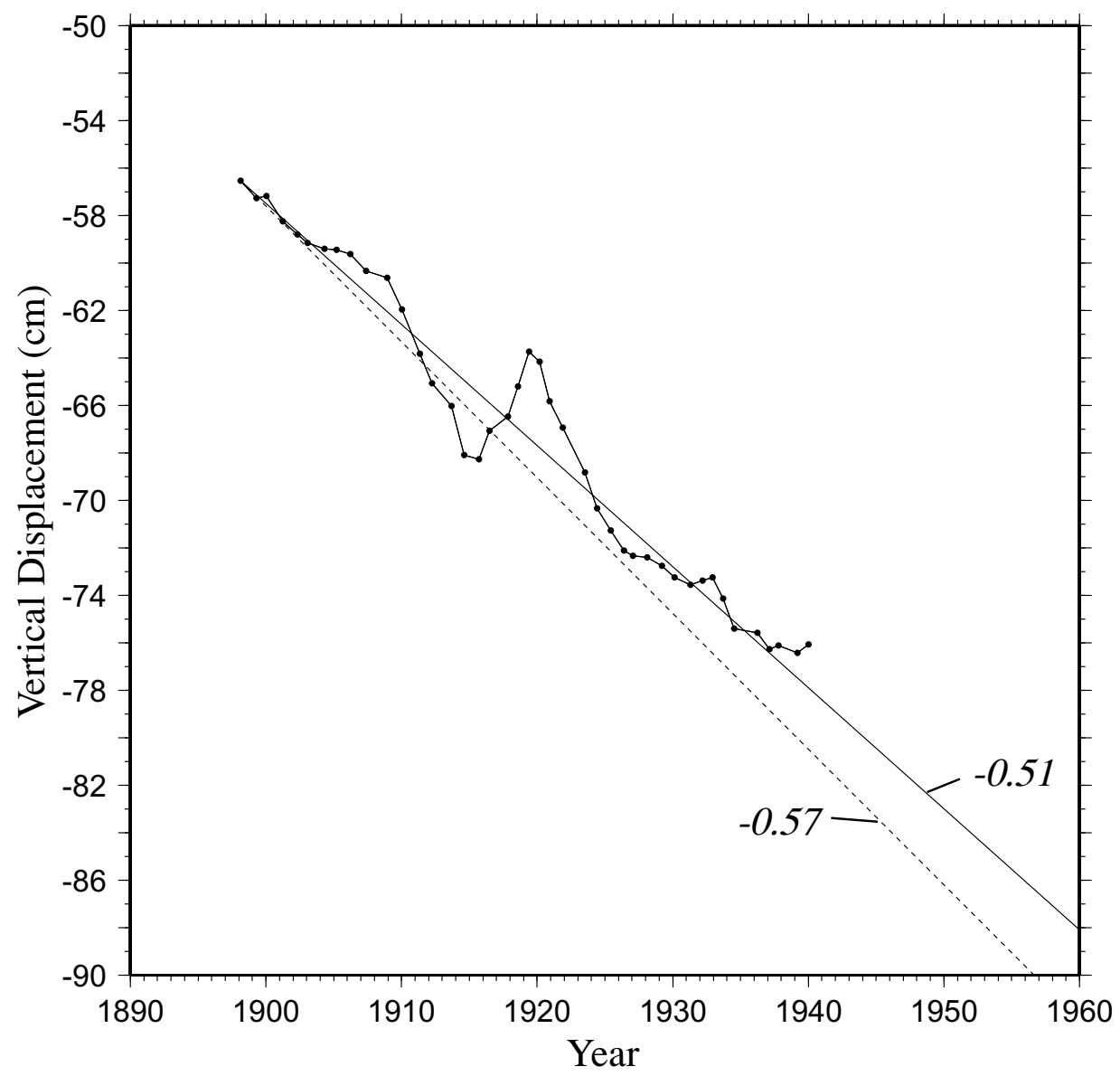

Fig. 7. Tide gauge data at Kushimoto (Coastal Movements Data Center, 2000). The signs are reversed and running-averaged for five points. The solid and dotted lines indicate the perturbed range of $v_{s}$. Numerals are in $\mathrm{cm} / \mathrm{yr}$.

degrees, because $V$ in Eq. (9) does not depend on degrees. The range of $v_{s}$ and the best-fitting for $(9,4)$ is shown in Fig. 5 by straight lines. I obtain $t_{f}=1922.9(-1.3,+1.4)$ and $1923.4(-1.1,+1.4)$ for $(9,4)$ and $(7,3)$, respectively, in which $t_{f}$ is the average value for $i=4 \sim N_{a}$ and the parentheses cover the $1 \sigma$ errors for $i=4 \sim N_{a}$. Figure 6 shows the residual uplifts for $v_{s}=-0.62 \mathrm{~cm} / \mathrm{yr}$, with the best-fitting curve for $(7,3)$ and $i=5$, which gives $t_{f}=$ 1923.6. Taking the average of $(9,4)$ and $(7,3)$, I estimate $t_{f}$ as $1923.2( \pm 1.6)$, of which the errors cover those of both cases.

The 1946 Nankai earthquake occurred on Dec. 21, 1946 (1947.0). This earthquake is the last event along the Nankai Trough, where great earthquakes have repeated in 100-200 years; interseismic and coseismic crustal deformations associated with this event have been studied extensively (Fitch and Scholz, 1971; Ando, 1975a; Thatcher, 1984; Miyashita, 1987; Matsu'ura and Sato, 1989; Yoshioka, 1991; Savage and Thatcher, 1992; Satake, 1993; Fukahata et al., 1996; Sagiya and Thatcher, 1999; Tanioka and Satake, 2001). The tip of Kii Peninsula had a coseismic uplift amounting to 50 $70 \mathrm{~cm}$ (Matsuzawa, 1964; Fitch and Scholz, 1971), and tilted oceanward during the interseismic periods. Although, to the west of the rupture zone, another event, the 1944 Tonankai earthquake $\left(M_{w} 7.9\right)$, occurred two years before the 1946 event, the effect of this event on crustal deformation at the tip of the peninsula can be neglected because it is located nearly at the hinge line of the coseismic deformation (Ishibashi, 1981).

Figure 7 shows the tide gauge data at Kushimoto during 1898.1-1940.0, for which signs are reversed and runningaveraged over 5 points (Coastal Movements Data Center, 2000). Although there are large fluctuations between 1900 and 1925, there might be residual uplifts during the decade or so prior to the 1946 event, as pointed out by Tada (1996). I apply the above method to these data to predict the time of occurrence of the 1946 earthquake. Steady subsidence is assumed in the range of $v_{s}$ between -0.51 and $-0.57 \mathrm{~cm} / \mathrm{yr}$ (Fig. 7). I assign $60 \mathrm{~cm}$ as $V_{e}$ (Matsuzawa, 1964; Fitch and Scholz, 1971). Pairs $(9,4)$ and $(7,3)$ are used. For this event, a subsidence rate that gives the minimum $\chi^{2}$ cannot be determined due to the large noises between 1900 and 1925 . Perturbing $v_{s}$ in the above range and $i$ between 4 and $N_{a}$ gives $t_{f}=1943.7( \pm 2.7)$. The parentheses cover the $1 \sigma$ errors for all the above cases when $\sigma$ of the data is assigned to be $1 \mathrm{~cm}$. Figure 8 shows the residual uplifts for $v_{s}=-0.54$ $\mathrm{cm} / \mathrm{yr}$ and the best-fitting curve for $(7,3)$ and $i=4$, which gives $t_{f}=1945.5$. 


\section{Kushimoto}

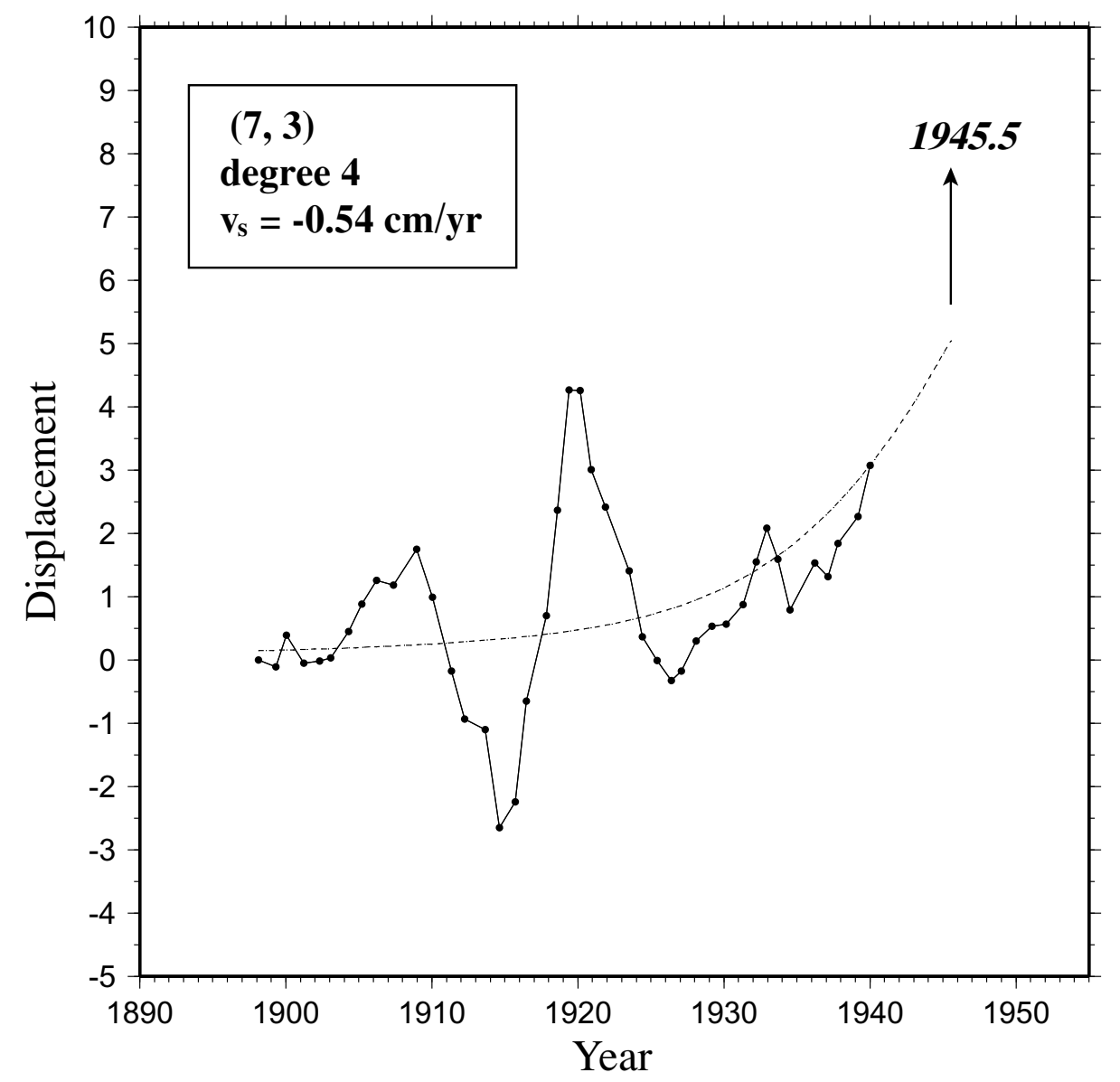

Fig. 8. Residual uplifts for $v_{s}=-0.54 \mathrm{~cm} / \mathrm{yr}$ and the best-fitting curve for $(7,3)$ and $i=4$, which gives $t_{f}=1945.5$.

\section{The Tokai Earthquake}

Precise leveling data of Hamaoka with respect to Kakegawa has been available since 1962 (Geographical Survey Institute, 2000); the data running-averaged over five points is shown in Fig. 9. The data from 1981.8 to 2001.8 are used because four measurements have been conducted per year for this period. Steady subsidence is assumed in the range of $v_{s}$ between -0.48 and $-0.60 \mathrm{~cm} / \mathrm{yr}$ through the first data point. I assign $60 \mathrm{~cm}$ as $V_{e}$, which is expected from the fault model of Ishibashi (1981). Because this event has not happened, there is uncertainty in $V_{e}$. If there is an uncertainty of 20 years in $t_{f}$, the expected uncertainty in $V_{e}$ would be about $20 \mathrm{yrs} \times 0.5 \mathrm{~cm} / \mathrm{yr}=10 \mathrm{~cm}$. Therefore, I perturbed $V_{e}$ from $50 \mathrm{~cm}$ to $70 \mathrm{~cm}$. Only cases $(9,4)$ and $(7,3)$ are considered for the same reason as the 1923 earthquake; in the case of the Tokai earthquake, for $N_{a}=9$, cases of $N_{b}>4$ make $\chi^{2}$ larger by 1.4 than that of $N_{b}=4$, and for $N_{a}=7$, cases of $N_{b}>3$ make $\chi^{2}$ larger by 1.7 than that of $N_{b}=3$. Smaller $N_{b}$ results in $p_{1}$ larger than $p_{c r}$. The earthquake degree is perturbed between 4 and $N_{a}$. I let the theoretical line go through the fourth data point from the last, because other points give much larger $\chi^{2} . v_{s}=-0.54$ $(-0.05,+0.03) \mathrm{cm} / \mathrm{yr}$ gives the minimum $\chi^{2}$ for both $(9$, $4)$ and $(7,3)$. The parentheses are $1 \sigma$ errors when $\sigma$ of the data is assigned to be $0.5 \mathrm{~cm}$. This range of $v_{s}$ and the best-fitting one is shown in Fig. 9 by straight lines. I obtain $t_{f}=2007.2(-5.0,+3.2)$ and $2008.0(-4.8,+2.2)$ for $(9$, 4 ) and $(7,3)$, respectively, of which $t_{f}$ is the average value for $i=4 \sim N_{a}, V_{e}=60 \mathrm{~cm}$, and $v_{s}=-0.54 \mathrm{~cm} / \mathrm{yr}$. The parentheses cover the $1 \sigma$ errors for all the cases perturbing $i, V_{e}$ and $v_{s}$, independently. Figure 10(a) shows the residual uplifts for $v_{s}=-0.54 \mathrm{~cm} / \mathrm{yr}$ and the best-fitting curve for $(9,4), i=6$, and $V_{e}=60 \mathrm{~cm}$, which gives $t_{f}=2007.3$. As an extreme case in the error range, Figure 10(b) shows the residual uplifts for $v_{s}=-0.59 \mathrm{~cm} / \mathrm{yr}$, and the best-fitting curve for $(9,4), i=9$, and $V_{e}=50 \mathrm{~cm}$, which gives $t_{f}=2002.2$. Finally, taking the average of $(9,4)$ and $(7$, 3 ), I obtain $t_{f}=2007.6(-5.4,+2.8)$, of which the errors cover those of both cases.

\section{Discussion}

Although I estimate $t_{f}$ for the Tokai earthquake to be around 2007 from the data in Fig. 9, it is obvious that I cannot conclude with certainty that the expected event occurs around this year. If the residual uplifts seen for the past several years decline gradually in the future, the prediction has to be prolonged. Figure 11 shows the tide gauge data at Aburatsubo after the 1923 earthquake, for which signs are reversed and running-averaged over 5 points (Coastal 


\section{Hamaoka-Kakegawa}



Fig. 9. Precise leveling data of Hamaoka with respect to Kakegawa since 1962 (Geographical Survey Institute, 2000); the data between 1981.8 and 2001.8 are used and running-averaged over five points. The dotted and chain lines indicate the $1 \sigma$ error range of the subsidence rate $v_{s}$. The solid line indicates $v_{s}$ with the minimum $\chi^{2}$. Numerals are in cm/yr. The residual uplifts became recognizable around 1990.

Movements Data Center, 2000). It can be seen that there are many fluctuations with periods of a few decades, similar to the residual uplifts prior to the 1923 shown in Fig. 5. Some of the fluctuations may be due to variations of oceanographic conditions, and others may represent crustal movements. Dambara (1973) in fact detected an undulation from 1955 to 1970 in the subsidence of Aburatsubo from the leveling data. Similarly, on the coast north of the 1944 Tonankai earthquake rupture zone (Fig. 1), Kimata et al. (2001) has observed three fluctuations in steady subsidence since the late 1970's with a period of ca. a decade using traditional geodesy. If I apply the above method to the fluctuations seen in Fig. 11, there will be many false alarms. Below I cite some other pieces of evidence that suggest that the Tokai earthquake may occur in the near future.

Seno (1979) pointed out that intraplate earthquakes in Southwest Japan tend to occur from ca. 50 years before a great interplate earthquake adjacent landward of its rupture zone. In the vicinity of the Tokai region, intraplate earthquakes started to occur around in 1957 (Seno, 1979, Fig. 5). This suggests the occurrence of the Tokai earthquake around 2007 , although the uncertainty is large.

Matsumura (2002) noted that the seismicity rate started to decrease around 1996 within the upper plate above the focal region of the Tokai earthquake, which had been in a remarkably steady state since the installation of dense seismometers in the early 1980's. He suggested that this may be related to stress changes at the plate interface in the focal area. The pattern of decrease of the seismicity rate is similar to the residual uplifts shown in Fig. 10(a), if decrease is taken to be positive, but with a ca. five-year delay. Slow failures of asperities may cause a re-distribution of stresses and the scale length of stress heterogeneity would become large at the plate interface, which might have resulted in the decrease of the seismicity rate of micro-earthquakes within the upper plate, with a possible delay due to viscous stress diffusion at the plate interface (Elsasser, 1967).

Rydelek and Sacks (2001) argued that the stress diffusion from the 1891 Nobi earthquake in central Japan has been affecting the Coulomb failure level of the Tokai earthquake, and brings it to a critical level around 2007 along with the loading of the subducting plate, although this inference seems to have a large uncertainty also.

Finally, I discuss the relation between the present model and the results of Igarashi (2000). Igarashi (2000) effectively applied log-periodic modulations in the power law formula 


\section{(a) Hamaoka-Kakegawa}

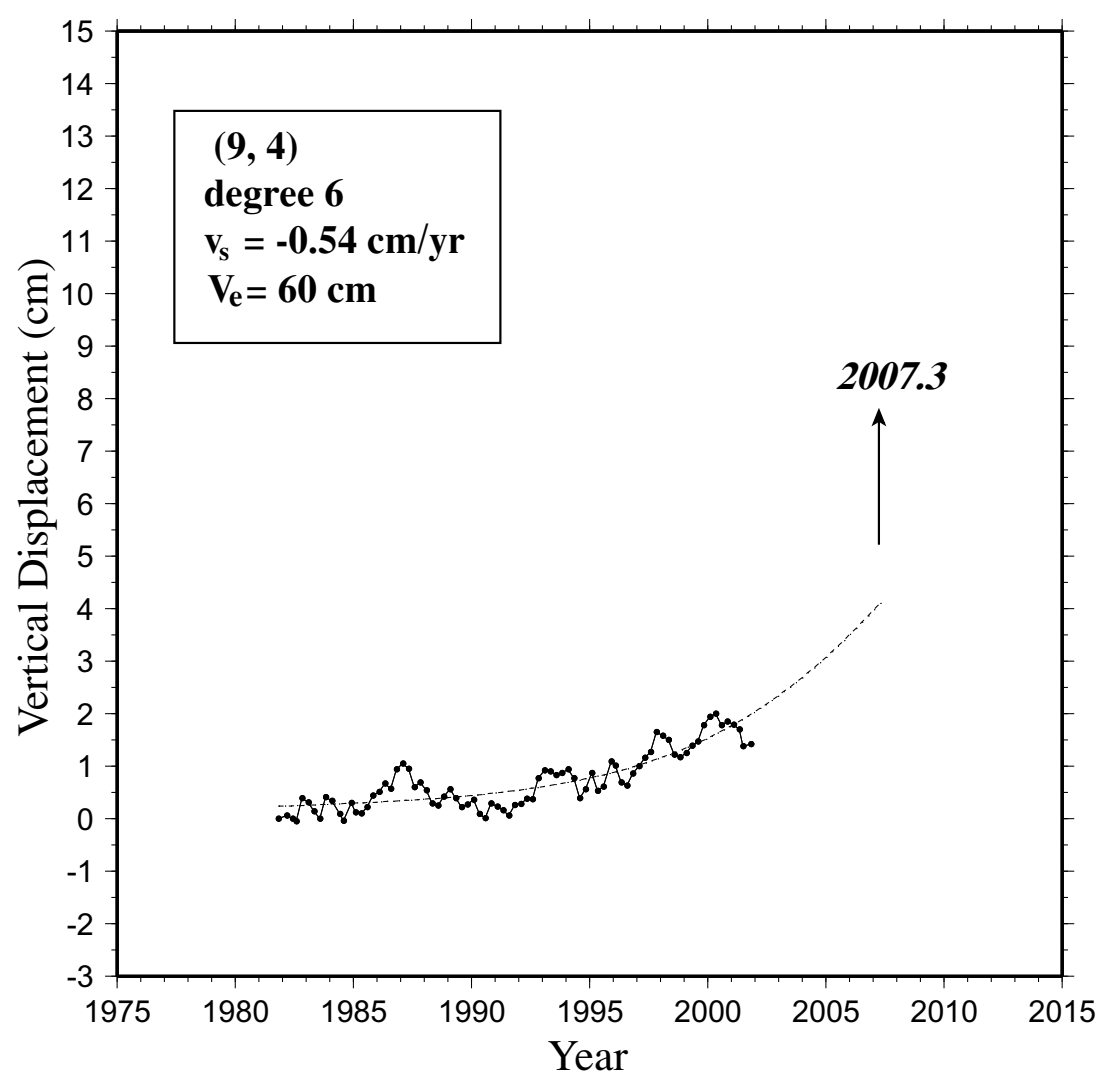

(b)

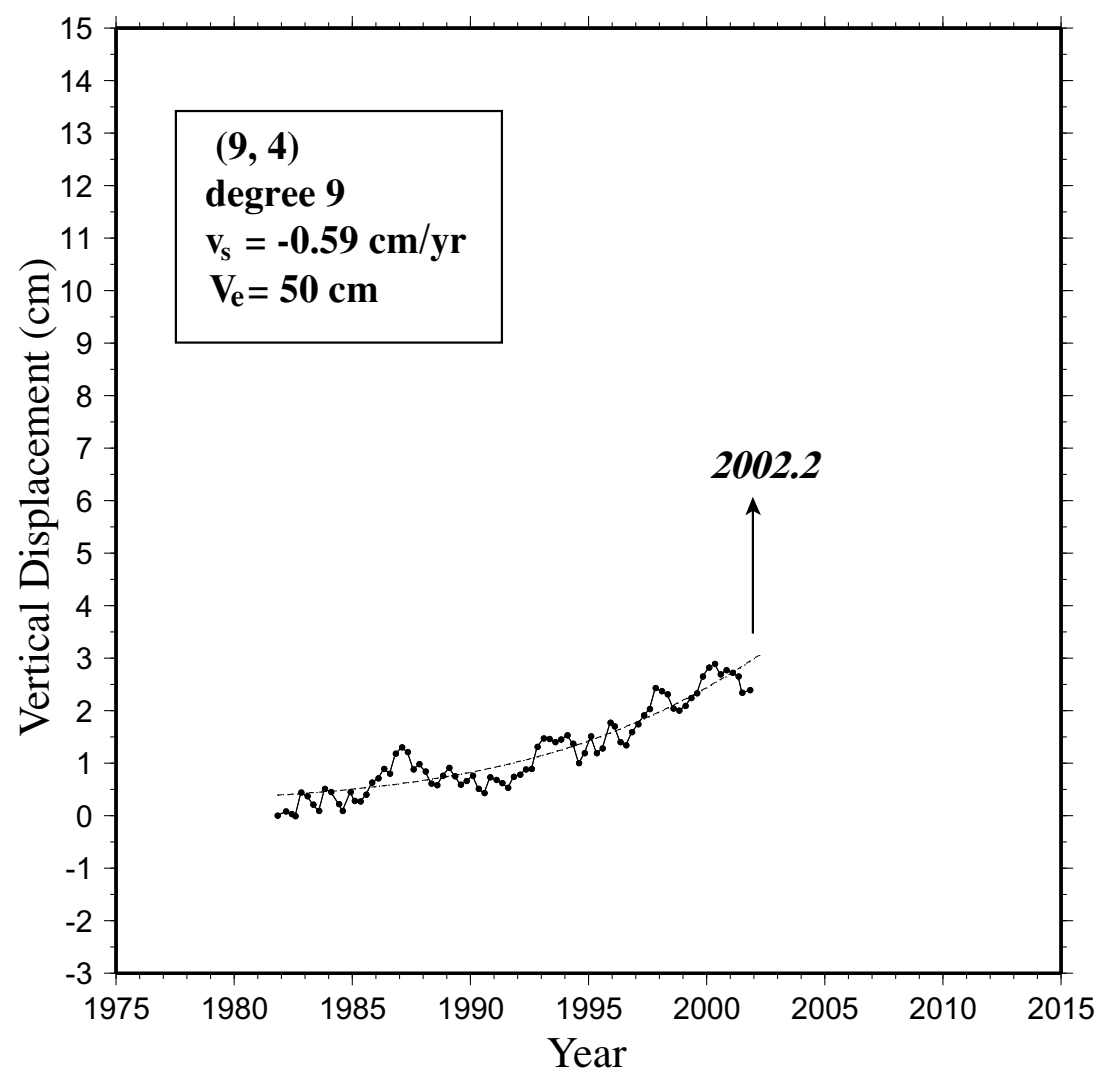

Fig. 10. (a) Residual uplifts for $v_{s}=-0.54 \mathrm{~cm} / \mathrm{yr}$ and the best-fitting curve for $(9,4), i=6$, and $V_{e}=60 \mathrm{~cm}$, which gives $t_{f}=2007.3$. (b) Residual uplifts for $v_{s}=-0.59 \mathrm{~cm} / \mathrm{yr}$, and the best-fitting curve for $(9,4), i=9$, and $V_{e}=50 \mathrm{~cm}$, which gives $t_{f}=2002.2$. 
Aburatsubo: After Kanto earthquake

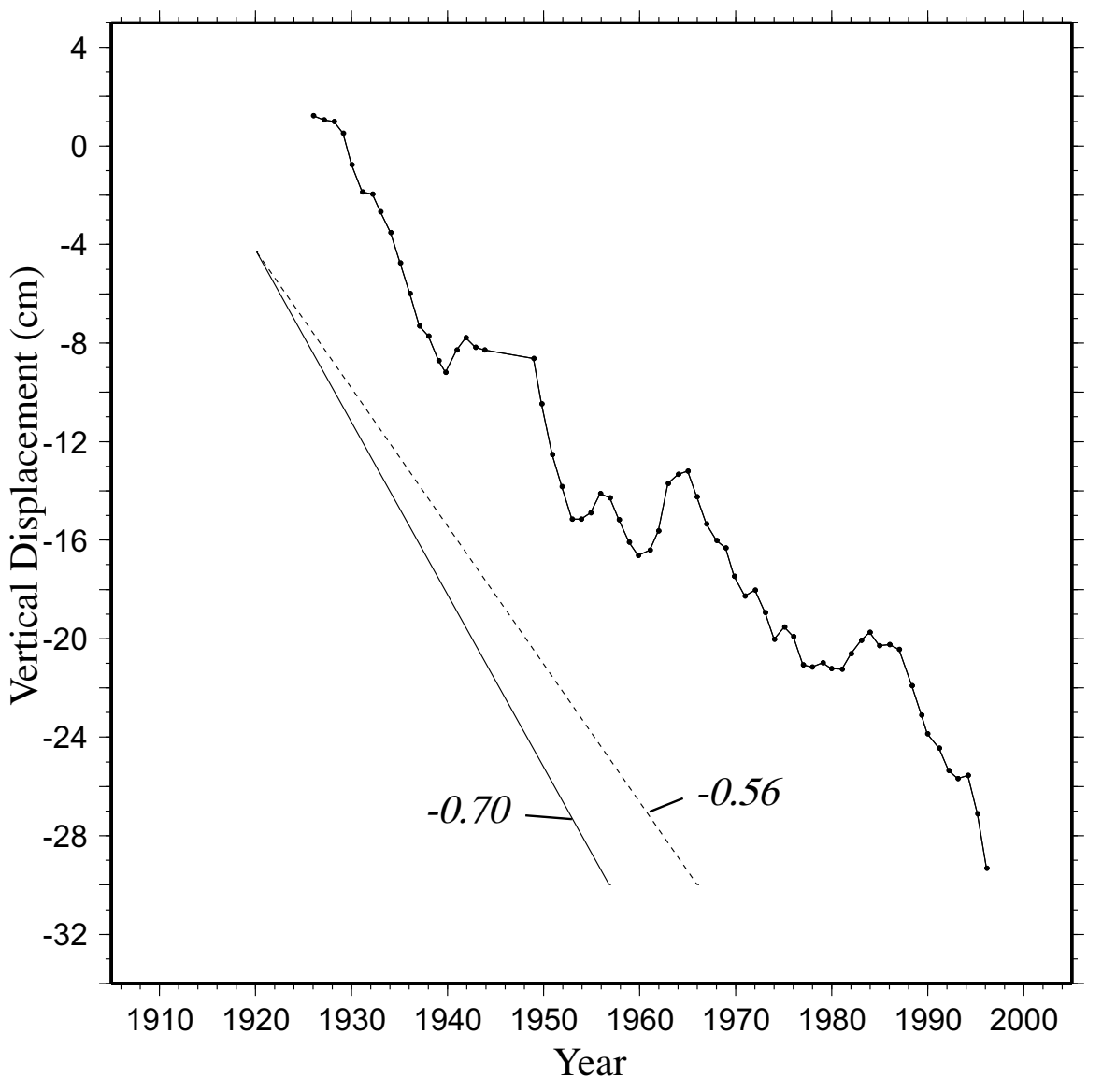

Fig. 11. Tide gauge data at Aburatsubo after the 1923 Kanto earthquake. There are fluctuations in subsidence rate with periods of a few decades. The dotted and solid lines indicate the $1 \sigma$ error range of $v_{s}$ prior to the 1923 earthquake. Numerals are in $\mathrm{cm} / \mathrm{yr}$.

to the leveling data from Hamaoka to Kakegawa to constrain the time of occurrence of the Tokai earthquake as a critical point. In the present study, $p_{f}$ is generally close to $p_{c r}$ (Fig. 4). On the other hand, $p_{\text {pre }}$ is still far from $p_{c r}$ for the best-fitting case of $t_{f}=2007$. However, in the extreme case as shown in Fig. 10(b), $p_{\text {pre }}$ is very close to $p_{c r}$, and a log-periodic modulation in the residual uplift data could be expected. Even in this case, however, the critical exponent and $\lambda$ in this study is 1 and 4.8, respectively, which are different from 0.44 and 1.6 obtained by Igarashi (2000). Therefore it is not straightforward to interpret his results in terms of the present model, although it certainly includes critical phenomena.

\section{Conclusions}

I construct a model to interpret the intermediate-term precursory uplifts of the tips of peninsulas in the Philippine Sea coast of Central-Southwest Japan, prior to great interplate earthquakes. This model assumes a fractal distribution of asperities and temporal changes of the frictional property of barriers at the plate interface. Using the fractal geometry obtained in the companion paper (Seno, 2003), I calculate uplifts due to slow failures of smaller asperities contained in a rupture zone, assuming that the probability of breakage of the smallest unit asperity increases linearly over time, and an asperity fails when more than a certain number of smaller asperities inside it fail.

Letting the time of breakage of one of the largest asperities be the time of occurrence of an earthquake $t_{f}$ as an unknown parameter, I conduct a least squares fitting to the residual uplift data prior to great earthquakes to constrain $t_{f}$. Applying this to the tide gauge data before the 1923 and 1946 earthquakes, I obtain $t_{f}=1923.2( \pm 1.6)$, and $1943.7( \pm 2.7)$, respectively. For the Tokai earthquake expected at the Suruga Trough, I obtain $t_{f}=2007.6(-5.4,+2.8)$ using the precise leveling data between Hamaoka and Kakegawa. Although there remains a possibility that the residual uplifts seen for the past 10 years might decline in the future, there are some pieces of evidence which suggest that the occurrence of the event is not far from the present. The subsidence of Hamaoka to Kakegawa should be continually and carefully monitored in the future. Because the present time is already in the error range of $t_{f}$, careful monitoring of the output from instruments in and near the focal area to detect short-term precursors should be continued as before. The intermediate-term precursors of a ca. 10 year period may be useful to limit the expected time of occurrence of coming great earthquakes, filling a gap between long-term and short-term earthquake predictions. 
Acknowledgments. I thank two anonymous reviewers and Jim Savage for their critical review of the manuscript, and Eiichi Fukuyama for useful comments. I thank George Igarashi for information on his models and discussions, and Geographical Survey Institute and Shozaburo Ozawa for providing the leveling data, and Shozo Matsumura for providing his unpublished materials and discussions.

\section{References}

Allegre, C. J., L. L. Le Mouel, and A. Provost, Scaling rules in rock fracture and possible implications for earthquake prediction, Nature, 297, 47-49, 1982.

Ando, M., A fault-origin model of the Great Kanto earthquake of 1923 as deduced from geodetic data, Bull. Earthq. Res. Inst., Univ. of Tokyo, 49 19-32, 1971.

Ando, M., Source mechanisms and tectonic significance of historical earthquakes along the Nankai Trough, Japan, Tectonophysics, 27, 119-140, $1975 \mathrm{a}$

Ando, M., Possibility of major earthquake in the Tokai district, Japan and its pre-estimated seismotectonic effects, Tectonophysics, 25, 69-85, $1975 \mathrm{~b}$.

Ariyoshi, K., N. Kato, and A. Hasegawa, Numerical simulation study on recent changes in crustal deformation and seismicity in the Tokai Area, central Japan, J. Geography, 110, 557-565, 2001 (in Japanese).

Boatwright, J. and M. Cocco, Frictional constraints on crustal faulting, $J$ Geophys. Res., 101, 13895-13909, 1996.

Coastal Movements Data Center, Tables and graphs of annual mean sea leve along the Japanese coast 1894-1998, Tokyo, 2000.

Dambara, T., Vertical movement of the crust at Aburatsubo, J. Geod. Soc Jpn, 19, 22-33, 1973.

Das, S. and K. Aki, Fault plane with barriers: A versatile earthquake model, J. Geophys. Res., 82, 5658-5670, 1977.

Dieterich, J. H., Modeling of rock friction 1. Experimental results and constitutive equations, J. Geophys. Res., 84, 2161-2168, 1979.

Dieterich, J. H. and B. D. Kilgore, Imaging surface contacts: Power law contact distributions and contact stresses in quartz, calcite, glass and acrylic plastic, Tectonophysics, 256, 219-239, 1996.

Elsasser, W. M., Convection and stress propagation in the upper mantle, in The Application of Modern Physics to the Earth and Planetary Interiors edited by S. K. Runcorn, pp. 223-246, John Wiley, New York, 1967.

Fitch, T. J. and C. H. Scholz, Mechanism of underthrusting in southwest Japan: A model of convergent plate interactions, J. Geophys. Res., 76 7260-7292, 1971.

Fukahata, Y., C. Honsho, and M. Matsu'ura, Crustal movements on Shikoku, southwestern Japan, inferred from inversion analysis of leveling data using ABIC, Tectonophysics, 257, 239-252, 1996.

Geographical Survey Institute, Crustal movements in the Tokai district, Rep. Coord. Comm. Earthquake Predict., 64, 256-285, 2000.

Henry, P., S. Mazzotti, and X. Le Pichon, Transient and permanent deformation of central Japan estimated by GPS 1. Interseismic loading and subduction kinematics, Earth Planet. Sci. Lett., 184, 443-453, 2001.

Igarashi, G., A geodetic sign of the critical point of stress-strain state at a plate boundary, Geophys. Res. Lett., 27, 1973-1976, 2000.

Imamura, A., Recurrence of seismic activity in the Kanto and Kinki districts and precursory phenomena preceding great earthquakes, Jisin, Ser. 1, 1, 4-16, 1929 (in Japanese).

Ishibashi, K., Specification of a soon-to-occur seismic faulting in the Tokai district, central Japan, based upon seismotectonics, Earthquake Prediction-An International Review, Maurice Ewing Series 4, 297-332, 1981.

Kato, N. and T. Hirasawa, A model for possible crustal deformation prior to a coming large interplate earthquake in the Tokai district, central Japan, Bull. Seism. Soc. Am., 89, 1401-1417, 1999.

Kawasaki, I. and Y. Okada, Prediction of time of occurrence of an earthquake-model and application to the Tokai earthquake_- The Earth Monthly, Spec. vol., 33, 149-158, 2001 (in Japanese).

Kayane, H. and T. Yoshikawa, Comparative study between present and emergent erosional landforms on the southeast coast of Boso peninsula central Japan, Geogr. Review Jpn, 59, 18-36, 1986 (in Japanese).

Kimata, F., N. Fujii, and K. Hirahara, Slow slip event detected from vertical movements by leveling and line length changes by EDM at the Tokai region in 1987, Abstr. Seism. Soc. Jpn, A41, 2001 (in Japanese)

Matsumura, S., Seismicity change in the inferred locked zone of Tokai in the latter half of 1990's, Jisin, 54, 449-463, 2002 (in Japanese).

Matsu'ura, M. and T. Sato, A dislocation model for the earthquake cycle at convergent plate boundaries, Geophys. J., 96, 23-32, 1989.
Matsuzawa, T., Study of Earthquakes, 213 pp., Uno Shoten, Tokyo, 1964.

Miyashita, K., A model of plate convergence in southwest Japan, inferred from leveling data associated with the 1946 Nankaido earthquake, $J$. Phys. Earth, 35, 449-467, 1987.

Mogi, K., Some features of recent seismic activity in and near Japan (2) Activity before and after great earthquakes, Bull. Earthq. Res. Inst., Univ of Tokyo, 47, 395-417, 1969.

Mogi, K., Recent horizontal deformation of the earth's crust and tectonic activity in Japan (1), Bull. Earthq. Res. Inst., Univ. of Tokyo, 48, 413430, 1970 .

Mogi, K., Earthquake Prediction, 355 pp., Academic Press Japan, Tokyo, 1985.

Nadeau, R. M. and L. R. Johnson, Seismological studies at Parkfield VI: Moment release rates and estimates of source parameters for small repeating earthquakes, Bull. Seism. Soc. Am., 88, 790-814, 1998.

Ohnaka, M., A sequence of seismic activity in the Kanto earthquake, $P A$ GEOPH, 122, 849-862, 1985.

Ohnaka, M. and L. Shen, Scaling of the shear rupture process from nucleation to dynamic propagation: Implications of geometric irregularity of the rupturing surfaces, J. Geophys. Res., 104, 817-844, 1999.

Rikitake, T., Probability of earthquake occurrence as estimated from crustal strain, Tectonophysics, 23, 299-312, 1974.

Ruina, A., Slip instability and state variable friction laws, J. Geophys. Res., 88, 10359-10370, 1983.

Rydelek, P. A. and I. S. Sacks, Stress diffusion from the 1891 Nobi and 1944 Tonankai earthquakes; implications for future failure of the Tokai fault, Eos Trans. Am. Geophys. Union, 82, S21B-0582, 2001.

Sagiya, T., Interplate coupling in the Tokai District, Central Japan, deduced from continuous GPS data, Geophys. Res. Lett., 26, 2315-2318, 1999.

Sagiya, T. and W. Thatcher, Coseismic slip resolution along a plate boundary megathrust: The Nankai Trough, southwest Japan, J. Geophys. Res., 104, 1111-1129, 1999.

Satake, K., Depth distribution of coseismic slip along the Nankai Trough, Japan, from joint inversion of geodetic and tsunami data, J. Geophys Res., 98, 4553-4565, 1993.

Savage, J. C., A dislocation model of strain accumulation and release at a subduction zone, J. Geophys. Res., 88, 4984-4996, 1983.

Savage, J. C. and W. Thatcher, Interseismic deformation at the Nankai Trough, Japan, subduction zone, J. Geophys. Res., 97, 11117-11135, 1992.

Sammis, C. G., R. M. Nadeau, and L. R. Johnson, How strong is an asperity?, J. Geophys. Res., 104, 10609-10619, 1999.

Seno, T., Pattern of intraplate seismicity in southwest Japan before and after great interplate earthquakes, Tectonophysics, 57, 267-283, 1979.

Seno, T., Fractal asperities, invasion of barriers, and interplate earthquakes, Earth Planets Space, 55, 649-665, 2003.

Seno, T., S. Stein, and A. E. Gripp, A model for the motion of the Philippine Sea plate consistent with NUVEL-1 and geological data, J. Geophys. Res., 98, 17941-17948, 1993.

Sornette, D., Critical Phenomena in Natural Sciences: Chaos, Fractals, Selforganization and Disorder: Concepts and Tools, 434 pp., Springer, 2000 .

Stuart, W. D., Forecast model for great earthquakes at the Nankai trough subduction zone, PAGEOPH, 126, 619-641, 1988.

Tada, T., Recent vertical crustal movements in the Tokai district and their implications, The Earth Monthly, Suppl., 14, 16-23, 1996 (in Japanese).

Tanioka, Y. and K. Satake, Coseismic slip distribution of the 1946 Nankai earthquake and aseismic slips caused by the earthquake, Earth Planets Space, 53, 235-241, 2001.

Thatcher, W., The earthquake deformation cycle at the Nankai Trough, southwest Japan, J. Geophys. Res., 89, 3087-3101, 1984.

Tse, S. T. and J. R. Rice, Crustal earthquake instability in relation to the depth variation of frictional slip properties, J. Geophys. Res., 91, 94529472, 1986

Tsubokawa, I., On relation between duration of crustal movement and magnitude of earthquake expected, J. Geod. Soc. Jpn., 15, 76-88, 1969.

Yoshioka, S., The interplate coupling and stress accumulation process of large earthquakes along the Nankai Trough, southwest Japan derived from geodetic and seismic data, Phys. Earth Planet. Inter., 66, 214-243, 1991.

Yoshioka, S., T, Yabuki, T. Sagiya, T. Tada, and M. Matsu'ura, Interplate coupling and relative plate motion in the Tokai district, central Japan, deduced from geodetic data inversion using ABIC, Geophys. J. Inter. 113, 607-621, 1993.

T. Seno (e-mail: seno@eri.u-tokyo.ac.jp) 